University of Wollongong

Research Online

Australian Institute for Innovative Materials -

Papers

Australian Institute for Innovative Materials

$1-1-2018$

\title{
Thermally Responsive Torsional and Tensile Fiber Actuator Based on Graphene Oxide
}

Hyunsoo Kim

Hanyang University

Ji Hwan Moon

Hanyang University

Tae Jin Mun

Hanyang University

Tae Gyu Park

Hanyang University

Geoffrey M. Spinks

University of Wollongong, gspinks@uow.edu.au

See next page for additional authors

Follow this and additional works at: https://ro.uow.edu.au/aiimpapers

Part of the Engineering Commons, and the Physical Sciences and Mathematics Commons

Research Online is the open access institutional repository for the University of Wollongong. For further information contact the UOW Library: research-pubs@uow.edu.au 


\title{
Thermally Responsive Torsional and Tensile Fiber Actuator Based on Graphene Oxide
}

\author{
Abstract \\ Graphene-based actuators are of practical interest because of their relatively low cost compared with \\ other nanocarbon materials, such as carbon nanotubes. We demonstrate the simple fabrication of \\ graphene oxide (GO)-based fibers with an infiltrated nylon-6,6 polymer by wet spinning. These fibers could \\ be twisted to form torsional actuators and further coiled to form tensile actuators. By controlling the \\ relative twisting and coiling direction of the $\mathrm{GO}$ /nylon fiber, we were able to realize reversible contraction \\ or elongation actuation with strokes as high as -80 and $75 \%$, respectively, when the samples were heated \\ to $200^{\circ} \mathrm{C}$. The tensile actuation showed a remarkably little hysteresis. Moreover, this $\mathrm{GO} /$ nylon actuator \\ could lift loads over 100 times heavier than itself and generate a stable actuation at high temperatures \\ over the melting point of the polymer. This novel kind of GO-based actuator, which has a multidirectional \\ actuation, has potential for a wide range of applications such as artificial muscles, robotics, and \\ temperature sensing.

\section{Disciplines} \\ Engineering | Physical Sciences and Mathematics

\section{Publication Details} \\ Kim, H., Moon, J. Hwan., Mun, T. Jin., Park, T. Gyu., Spinks, G. M., Wallace, G. G. \& Kim, S. Jeong. (2018). \\ Thermally Responsive Torsional and Tensile Fiber Actuator Based on Graphene Oxide. ACS Applied \\ Materials and Interfaces, 10 32760-32764.

\section{Authors} \\ Hyunsoo Kim, Ji Hwan Moon, Tae Jin Mun, Tae Gyu Park, Geoffrey M. Spinks, Gordon G. Wallace, and \\ Seon Jeong Kim
}


Thermally Responsive Torsional and Tensile Fiber-actuator Based on Graphene Oxide

Hyunsoo Kim ${ }^{1 \dagger}$, Ji Hwan Moon ${ }^{1 \dagger}$, Tae Jin Mun ${ }^{1}$, Tae Gyu Park ${ }^{1}$, Geoffrey. M. Spinks ${ }^{2}$, Gordon. G. Wallace ${ }^{2}$, Seon Jeong Kim ${ }^{1 *}$

${ }^{1}$ Center for Self-Powered Actuation, Department of Biomedical Engineering, Hanyang University, Seoul 04763, Korea

${ }^{2}$ Intelligent Polymer Research Institute, ARC Centre of Excellence for Electromaterials Science, AIIM Facility, Innovation Campus, University of Wollongong, North Wollongong, NSW 2522, Australia

*E-mail: sjk@hanyang.ac.kr

${ }^{\dagger}$ H. Kim and J. H. Moon contributed equally to this work 


\begin{abstract}
Graphene based actuators are of practical interest because of their relatively low cost compared with other nano-carbon materials, such as carbon nanotubes. We demonstrate the simple fabrication of graphene oxide (GO)-based fibers with infiltrated Nylon-6,6 polymer by wet-spinning. These fibers could be twisted to form torsional actuators and further coiled to form tensile actuators. By control the relative twisting and coiling direction of the GO/Nylon fiber, we were able to realise reversible contraction or elongation actuation with strokes as high as $-80 \%$ and $75 \%$, respectively, when the samples were heated to $200^{\circ} \mathrm{C}$. The tensile actuation showed remarkably little hysteresis. Moreover, this GO/Nylon actuator could lift loads over 100 times heavier than itself, and generate stable actuation at high temperatures over the melting point of the polymer. This novel kind of GO-based actuator, which has multi-directional actuation, have potential for a wide range of applications such as artificial muscles, robotics, and temperature sensing.
\end{abstract}

Keyword: Graphene oxide, nylon, torsion, tensile, actuation, temperature 


\section{Introduction}

Carbon materials have recently attracted considerable attention due to their remarkable physical properties including high strength, electrical and thermal conductivity, and flexibility. Fiber type carbon materials have been developed by many researchers for various applications such as supercapacitors, ${ }^{1,2}$ batteries $^{3}$, and artificial muscles. $^{4-6}$ In previous research, we demonstrated large stroke (16.5\%) and high efficiency $(5.4 \%)$ of tensile artificial muscles using carbon nanotube yarn which was fabricated by twisting a sheet drawn from a CNT forest. ${ }^{7}$ However, the high cost of CNTs limits their use and we were motivated to investigate the actuation of twisted fibers made from lower cost graphene oxide (GO). The GO is the oxidised form of graphite and contains oxygen functional groups such as hydroxyl groups and carboxylic acid groups that render the material soluble in certain solvents. Laminating GO with an inert polymer provides the means to fabricate bilayer bending and folding actuators that can be driven by water desorption or when heated, respectively. ${ }^{8,9}$ Cheng et al. demonstrated moisture triggered bending and torsional actuation by twisting GO fibers that had been fabricated by wet-spinning a liquid crystalline (LC) GO solution. ${ }^{10}$ Wet spinning is a simple method amenable to mass production. ${ }^{11-13}$ Graphene based actuators reported to date show torsional or bending motions but tensile actuation is preferred in applications such as robotics, and artificial muscles.

In this paper, we demonstrate free-standing torsional and tensile actuation of GObased composite fibers that incorporate infiltrated Nylon polymer. Nylon has a high coefficient of thermal expansion $\left(\sim 80 \times 10^{-6} \mathrm{~K}^{-1}\right)$ and is widely used as a material for thermally-driven artificial muscles. ${ }^{14,15}$ The GO-based tensile actuators were fabricated by wet-spinning LCGO solution into a Nylon polymer solution coagulation bath. The 
ultra large GO sheets were easy to wet-spun and produced strong LCGO/Nylon fibers. Tensile actuators were made by first twisting the LCGO/Nylon fiber and then forming the twisted fiber into a coil shape. Heating and cooling the twisted and coiled LCGO/Nylon fibers showed reversibility of $\sim 80 \%$ without hysteresis. Additionally, homochiral tensile actuators (the chirality of fiber twist matches the coil's chirality) showed contraction on heating and heterochiral tensile actuators (the chirality of fiber twist was opposite to the coil's chirality) elongated when heated. ${ }^{14}$ Finally, the highly aligned large LCGO sheets could maintain their structural integrity even at high temperatures over melting point of the Nylon. These free-standing and structurally stable actuators may have potential in artificial muscles, robotics, and temperature sensors.

\section{Results and discussion}

The LCGO/Nylon tensile actuator was fabricated by twisting (fig. 1a) and winding (fig. 1b,c) to form coils. The wet-spun precursor LCGO/Nylon fiber was produced by extruding the LCGO aqueous solution (1 wt. \%) into a slowly rotating coagulation bath of Nylon-6,6 in trifluoroacetic acid (5 wt. \%). At this concentration the LCGO with an average flake dimension of $\sim 37 \pm 23 \mu \mathrm{m}$ was in the liquid crystalline form. After soaking, washing and drying the precursor LCGO/Nylon fibers were twisted in the $\mathrm{S}$ direction and then wrapped around a glass tube and heat set at $220^{\circ} \mathrm{C}$ for 2 hours. The wrapping was either in the $\mathrm{S}$ direction or $\mathrm{Z}$ direction to produce tensile actuators capable of contraction (S-S homochiral) (fig. 1b) or elongation (S-Z heterochiral) (fig. 1c)

when heated. Figure 1d, e shows the scanning electron microscopy images for mandrel coiled homochiral and heterochiral LCGO/Nylon fibers, respectively.

The tensile actuation was induced by volume expansion of the guest material in fiber. When LCGO/Nylon tensile actuator is heated, the volume of the Nylon polymer 
increased, which increased the separation between GO flakes since the Nylon occupies the interstices between GO flakes. This volume expansion of the composite fiber induces torsional actuation by rotation in the untwisting direction. ${ }^{4}$ The fiber torsion is translated into coil tensile actuation with contracting actuation, which pulls coils together, occurring in the homochiral structure. In contrast, the heterochiral structure shows elongation, which pushes coils, because its direction of rotation is opposite to homochiral structure. This mechanism is previously reported using twisted polymer fiber artificial muscles. ${ }^{14}$

The mechanical properties of the LCGO/Nylon fiber were evaluated by tensile testing and the stress-strain curve is shown in fig. 2a. By increase the wt $\%$ of the LCGO, fiber strength and elastic modulus is increased. In this work, the fiber is optimized $1 \mathrm{wt} \%$ LCGO fiber owing to the highest mechanical toughness that can be twistable and strong. The mechanical toughness estimated by the work to fracture in the tensile test (10.6 $\mathrm{MJ} / \mathrm{m}^{3}$ ) is higher than previously reported GO fibers which includes graphene, ${ }^{16}$ reduced GO treated with $\mathrm{Mg}^{2+},{ }^{17}$ neat reduced GO fiber, ${ }^{18}$ and GO-based composite fibers such as reduced GO-PGMA. ${ }^{19}$ The elastic modulus of $\sim 5 \mathrm{GPa}$ is higher than neat Nylon due to the reinforcing effect of the GO. The fibers showed an ultimate strength of $\sim 148 \mathrm{MPa}$ and $\sim 10 \%$ elongation at break. The cross section of the LCGO/Nylon fiber shows edge planes of the GO flakes indicating that the GO is aligned along the fiber (fig. 2b). This structure is attributed to LC alignment in the spinning solution that is preserved during wet-spinning due to large sheet size of the GO. ${ }^{20}$ The edge planes also show a wrinkled structure that can increase toughness by contributing to sliding or slip between aligned LCGO sheets. ${ }^{21}$

To investigate the structure and degree of infiltration of the Nylon into the LCGO fiber, the LCGO/Nylon fiber was characterized by Raman spectroscopy and thermal 
analysis. The Raman spectrum of the cross section of the LCGO/Nylon fiber in fig. 2c shows typical D band $\left(1350 \mathrm{~cm}^{-1}\right)$ and $\mathrm{G}$ band $\left(1580 \mathrm{~cm}^{-1}\right)$ which are related to $\mathrm{sp}^{3}$ and $\mathrm{sp}^{2}$ bond of the LCGO. A peak corresponding to the $\mathrm{CH}_{2}$ stretching bond in Nylon is found at $2900 \mathrm{~cm}^{-1}$. Fig. $2 \mathrm{~d}$ is a thermal degradation behavior of the LCGO, Nylon, and LCGO/Nylon fiber as determined by thermogravimetric analysis (TGA). The weight of the neat Nylon dramatically decreased by $\sim 80 \mathrm{wt} \%$ at $\sim 380^{\circ} \mathrm{C}$ and a secondary weight loss was observed above $\sim 480^{\circ} \mathrm{C}$. In the case of the LCGO, some of water evaporation and decomposition of labile oxygen functional groups ${ }^{22}$ is evident by the significant weight loss $(\sim 39 \mathrm{wt} \%)$ observed below $200^{\circ} \mathrm{C}$. The LCGO/Nylon composite fiber shows a combination of these degradation profiles and the content of the infiltrated Nylon can be estimated at $20-40 \mathrm{wt} \%$.

Before demonstrating the tensile actuation, it is important to confirm the torsional actuation because the torsion is the basic mechanism that drives the tensile actuation in the coiled fibers. Fig. 3a shows torsional actuation stroke of the twisted LCGO/Nylon fibers prepared with different amounts on inserted twist. The torsional stroke obtained when the fibers were heated from room temperature to $200^{\circ} \mathrm{C}$, increased almost linearly with twist and measured $63,84,104$, and $148.5^{\circ}$ for the $133,266,400$, and 533 turns/m, respectively. The measured bias angle is $\sim 26^{\circ}$ for the maximum twisted LCGO/Nylon fiber surface. The torsional actuation of the LCGO/Nylon fibers were fully reversible during heat and cool cycles, as shown in movie 1 . The full reversibility is achieved in the LCGO/Nylon twisted fibers without fixing the ends of the fiber. Generally, previous yarn or fiber types of the torsional actuators have been operated with both ends fixed to prevent untwisting when actuating. The combined GO flake scaffold and the infiltrated Nylon 
both act to expand elastically during thermal cycles and ensure recoverability of the starting structure on cooling.

After winding the twisted LCGO/Nylon fiber to form the two types of coils (homochiral and heterochiral) the contraction and elongation of the tensile actuations were observed, respectively (fig. 3b). Coils were formed by wrapping the twisted fiber around mandrels of different diameters so as to vary the coil spring index, which is the ratio of the coil diameter to the fiber diameter. The tensile actuation stroke increased by increasing the spring index and the maximum was $-80 \%$ for 24.9 spring index homochiral coil. The equivalent heterochiral coil generated a stroke of $+75 \%$ with a positive stroke indicating expansion. The reversibility of thermal actuation of the homochiral and heterochiral LCGO/Nylon by heating and cooling between $25^{\circ} \mathrm{C}$ and $200^{\circ} \mathrm{C}$ are shown in fig. 3c. The both homochiral and heterochiral LCGO/Nylon actuators exhibit reversible tensile actuation without hysteresis (movie 2) even when fixed at only one end. This remarkable absence of hysteresis is highly desirable in application for robotics, artificial muscle, and temperature sensors, where precise control is needed. As the possibility for those applications, sensitivity and precision were calculated as a $\sim 0.43 \% /{ }^{\circ} \mathrm{C}$ and $\sim 1.9 \%$, respectively. When a $\mathrm{Cu}$ plate load was attached to the free end of a heterochiral coiled LCGO/Nylon actuator (spring index: 16.5), it was able to raise and lower this mass with a tensile stroke of $12.7 \%$ (movie 3) (fig. 3d). This $\mathrm{Cu}$ plate was 116 times heavier than the fiber and the actuation remained fully reversible.

The thermal stability of the LCGO/Nylon actuation is illustrated by the reversible tensile actuation achieved by heating above the melting temperature of the Nylon. Fig. 4a shows comparative actuation during heating of heterochiral coiled Nylon and LCGO/Nylon fiber actuators. When heated the LCGO/Nylon mandrel coil elongated 
along the coil axis while the Nylon fiber coil was observed to elongate and bow sideways even at temperatures well below melting. Continued heating to above the melting point of the Nylon $6 / 6\left(250-260^{\circ} \mathrm{C}\right)$ caused collapse of the Nylon fiber coil, but the LCGO/Nylon retained its coil structure. This stability at high temperature results from the scaffold structure formed from the interconnected GO sheets within the composite fiber. The Nylon infiltrates within this scaffold structure and is confined between GO. The structural integrity of the GO framework ensures that the coil shape can be sustained even if the temperature raises above the melting point of the Nylon (fig. $4 \mathrm{~b}$ ).

\section{Conclusion}

In summary, we have demonstrated a dual torsional and tensile actuation in a twisted GO-based composite fiber that was driven by thermal stimuli. The fibers were fabricated using a scalable wet-spinning technique where Nylon in the coagulation bath was readily infiltrated within interstices in the GO framework structure. The thermal actuation was induced by volume expansion of the infiltrated Nylon polymer. As a result, the LCGO/Nylon tensile actuator shows reversible torsional and tensile actuation when heated and cooled. The tensile actuation stroke reaches $\sim 80 \%$ contraction (homochiral structure) and $\sim 75 \%$ elongation (heterochiral structure) without hysteresis. These LCGO/Nylon actuators were capable of lifting over 100 times heavier load than their own mass. Additionally, on the basis of highly aligned LCGO along the fiber, the LCGO/Nylon actuator shows stable actuation and can withstand temperatures over the melting point of the Nylon polymer. Accordingly, these torsional and tensile GO-based actuators have potential as artificial muscles but also as temperature indicators. These attractive features are further supplemented by the relatively low cost of GO in comparison with other carbon materials such as carbon nanotubes. 


\section{Experimental section}

Preparation of materials. Liquid crystalline graphene oxide (LCGO) was dispersed in water and was prepared by previously reported methods. ${ }^{20,23}$ The Nylon 6/6 was purchased from Sigma-Aldrich (USA). A trifluoroacetic acid (TFA) $\left(\mathrm{CF}_{3} \mathrm{CO}_{2} \mathrm{H}\right.$, 99.5+\%) solvent for the Nylon 6/6 was purchased from Alfa Aesar (USA).

Fabrication of LCGO/Nylon actuator. To develop LCGO/Nylon fiber, we employed a wet spinning system that consisted of a syringe pump to extrude the $1 \mathrm{wt} \%$ LCGO aqueous solution into a rotating coagulation bath filled with the Nylon 6/6 (5 wt $\%)$ solution in TFA. The wet spinning condition for fabricating LCGO/Nylon fibers used an extrusion speed of $15 \mathrm{ml} / \mathrm{h}$ for the LCGO aqueous solution through a 26-gauge needle from the syringe pump. The rotating speed of the coagulation bath was $8 \mathrm{rpm}$. After wet spinning, the as-spun LCGO fiber was left to soak in the coagulation bath overnight to allow the Nylon polymer to fully infiltrate into the LCGO fiber. After soaking, the Nylon LCGO fiber goes through a washing process using TFA:acetone (1:1) solution followed by a drying process. Next, the LCGO/Nylon tensile actuators were fabricated by twisting to the desired level of inserted twist and wound onto glass rod mandrels to form coils. Finally, the samples were thermal annealed at $220^{\circ} \mathrm{C}$ for 2 hours in the vacuum oven, cooled to room temperature and the mandrel removed.

Characterization. The surface morphologies of the LCGO/Nylon fiber were obtained by scanning electron microscopy (SEM) (Hitachi S4700, Japan). The Raman spectra of the LCGO, Nylon, and the cross-section of the LCGO/Nylon fiber were obtained with a Raman spectrometer (LabRam Aramis, Horiba Jobin Yvon) using 514.5 nm excitation. The stress-strain curve was measured using a universal testing machine 
(Shimadzu model: EZ-SX, Japan) and the tensile testing was performed using a loading rate of $1 \mathrm{~mm} / \mathrm{min}$. Thermogravimetric analysis (SDT Q600, TA instruments, USA) of the LCGO, Nylon, and LCGO/Nylon fiber were measured from room temperature to $800{ }^{\circ} \mathrm{C}$, at a rate of $10{ }^{\circ} \mathrm{C} / \mathrm{min}$ in air. The sensitivity and precision were calculated by slope and error of the temperature versus strain curves using fitting.

\section{Conflict of interest}

There are no conflicts to declare.

\section{Supporting Information}

Movies demonstrating the reversible torsional, tensile, and lifting actuation of the LCGO/Nylon actuator.

\section{ORCID}

Seon Jeong Kim: 0000-0002-2867-6737

\section{Acknowledgement}

This work was supported by the Creative Research Initiative Center for SelfPowered Actuation in Korea. Additional support was from the Australian Research Council and the Australian National Fabrication Facility. Also, H. Kim and J. H. Moon contributed equally to this work. 


\section{Reference}

(1) Choi, C.; Lee, J. A.; Choi, A. Y.; Kim, Y. T.; Lepró, X.; Lima, M. D.; Baughman, R. H.; Kim, S. J. Flexible Supercapacitor Made of Carbon Nanotube Yarn with Internal Pores. Adv. Mater. 2014, 26, 2059-2065.

(2) Choi, C.; Lee, J. M.; Kim, S. H.; Di, J.; Baughman, R. H.; Kim, S. J. Twistable and Stretchable Sandwich Structured Fiber for Wearable Sensors and Supercapacitors. Nano Lett. 2016, 16, 7677-7684.

(3) Weng, W.; Sun, Q.; Zhang, Y.; Lin, H.; Ren, J.; Lu, X.; Wang, M.; Peng, H. Winding Aligned Carbon Nanotube Composite Yarns into Coaxial Fiber Full Batteries with High Performances. Nano Lett. 2014, 14, 3432-3438.

(4) Foroughi, J.; Spinks, G. M.; Wallace, G. G.; Oh, J.; Kozlov, M. E.; Fang, S.; Mirfakhrai, T.; Madden, J. D. W.; Shin, M. K.; Kim, S. J.; Baughman, R. H. Torsional Carbon Nanotube Artificial Muscles. Science, 2011, 334, 494-497.

(5) Lee, S.-H; Kim, T. H.; Lima, M. D.; Baughman, R. H.; Kim, S. J. Biothermal Sensing of a Torsional Artificial Muscle. Nanoscale, 2016, 8, 3248-3253.

(6) Lima, M. D.; Li, N.; Andrade, M. J.; Fang, S.; Oh, J.; Spinks, G. M.; Kozlov, M. E.; Haines, C. S.; Suh, D.; Foroughi, J.; Kim, S. J.; Chen, Y.; Ware, T.; Shin, M. K.; Machado, L. D.; Fonseca, A. F.; Madden, J. D. W.; Voit, W. E.; Galvão, D. S.; Baughman, R. H. Electrically, Chemically, and Photonically Powered Torsional and Tensile Actuation of 
Hybrid Carbon Nanotube Yarn Muscles. Science, 2012, 338, 928-932.

(7) Lee, J. A.; Li, N.; Haines, C. S.; Kim, K. J.; Lepró, X.; O.-Robles, R.; Kim, S. J.; Baughman, R. H. Electrochemically Powered, Energy-Conserving Carbon Nanotube Artificial Muscles. Adv. Mater. 2017, 29, 1700870.

(8) Liang, J.; Huang, L.; Li, N.; Huang, Y.; Wu, Y.; Fang, S.; Oh, J.; Kozlov, M.; Ma, Y.; Li, F.; Baughman, R.; Chen, Y. Electromechanical Actuator with Controllable Motion, Fast Response Rate, and High-Frequency Resonance Based on Graphene and Polydiacetylene. ACS Nano, 2012, 6, 4508-4519.

(9) Mu, J.; Hou, C.; Wang, H.; Li, Y.; Zhang, Q.; Zhu, M. Origami-Inspired Active Graphene-Based Paper for Programmable Instant Self-Folding Walking Devices. Sci. Adv. 2015, 1, e1500533.

(10) Cheng, H.; Hu, Y.; Zhao, F.; Dong, Z.; Wang, Y.; Chen, N.; Zhang, Z.; Qu, L. Moisture-Activated Torsional Graphene-Fiber Motor. Adv. Mater. 2014, 26, 2909-2913.

(11) Aboutalebi, S. H.; Jalili, R.; Esrafilzadeh, D.; Salari, M.; Gholamvand, Z.; Yamini, S. A.; Konstantinov, K.; Shepherd, R. L.; Chen, J.; Moulton, S. E.; Innis, P. C.; Minett, A. I.; Razal, J. M.; Wallace, G. G. High-Performance Multifunctional Graphene Yarns: Toward Wearable All-Carbon Energy Storage Textiles. ACS Nano, 2014, 8, 2456-2466.

(12) Liu, Z.; Xu, Z.; Hu, X.; Gao, C. Lyotropic Liquid Crystal of Polyacrylonitrile- 
Grafted Graphene Oxide and Its Assembled Continuous Strong Nacre-Mimetic Fibers. Macromolecules. 2013, 46, 6931-6941.

(13) Kim, H.; Jalili, R.; Spinks, G. M.; Wallace, G. G.; Kim, S. J. High-Strength Graphene and Polyacrylonitrile Composite Fiber Enhanced by Surface Coating with Polydopamine. Composites Science and Technology, 2017, 149, 280-285.

(14) Haines, C. S.; Lima, M. D.; Li, N.; Spinks, G. M.; Foroughi, J.; Madden, J. D. W.; Kim, S. H.; Fang, S.; Andrade, M. J.; Göktepe, F.; Göktepe, Ö.; Mirvakili, S. M.; Naficy, S.; Lepró, X.; Oh, J.; Kozlov, M. E.; Kim, S. J.; Xu, X.; Swedlove, B. J.; Wallace, G. G.; Baughman, R. H. Artificial Muscles from Fishing Line and Sewing Thread. Science, 2014, $343,868-872$.

(15) Haines, C. S.; Li, N.; Spinks, G. M.; Aliev, A. E.; Di, J.; Baughman, R. H. New Twist on Artificial Muscles. PNAS, 2016, 113, 11709-11716.

(16) Sun, J.; Li, Y.; Peng, Q.; Hou, S.; Zou, D.; Shang, Y.; Li, Y.; Li, P.; Du, Q.; Wang, Z.; Xia, Y.; Xia, L.; Li, X.; Cao, A. Macroscopic, Flexible, High-Performance Graphene Ribbons. ACS Nano, 2013, 7, 10225-10232.

(17) Hu, X.; Xu, Z.; Gao, C. Multifunctional, Supramolecular, Continuous Artificial Nacre Fibres. Sci. Rep. 2012, $2,767$.

(18) Xu, Z.; Gao, C. Graphene Chiral Liquid Crystals and Macroscopic Assembled Fibres. 
Nat. Commun. 2011, 2, 571.

(19) Zhao, X.; Xu, Z.; Zheng, B.; Gao, C. Macroscopic Assembled, Ultrastrong and $\mathrm{H}_{2} \mathrm{SO}_{4}$-Resistant Fibres of Polymer-Grafted Graphene Oxide. Sci. Rep. 2013, 3, 3164.

(20) Jalili, R.; Aboutalebi, S. H.; Esrafilzadeh, D.; Konstantinov, K.; Razal, J. M.; Moulton, S. E.; Wallace, G. G. Formation and Processability of Liquid Crystalline Dispersions of Graphene Oxide. Mater. Horiz. 2014, 1, 87-91.

(21) Shin, M. K.; Lee, B.; Kim, S. H.; Lee, J. A.; Spinks, G. M.; Gambhir, S.; Wallace, G. G.; Kozlov, M. E.; Baughman, R. H.; Kim, S. J. Synergistic Toughening of Composite Fibres by Self-Alignment of Reduced Graphene Oxide and Carbon Nanotubes. Nat. Commun, 2012, 3, 650.

(22) Lee, S.; Park, S. Facile Mass Production of Thermally Reduced Graphene Oxide. Carbon Letters, 2012, 13, 45-50.

(23) Jalili, R.; Aboutalebi, S. H.; Esrafilzadeh, D.; Shepherd, R. L.; Chen, J.; A.-Yamini, S.; Konstantinov, K.; Minett, A. I.; Razal, J. M.; Wallace, G. G. Scalable One-Step WetSpinning of Graphene Fibers and Yarns from Liquid Crystalline Dispersions of Graphene Oxide: Towards Multifunctional Textiles. Adv. Funct. Mater. 2013, 23, 5345-5354. 


\section{Figures}

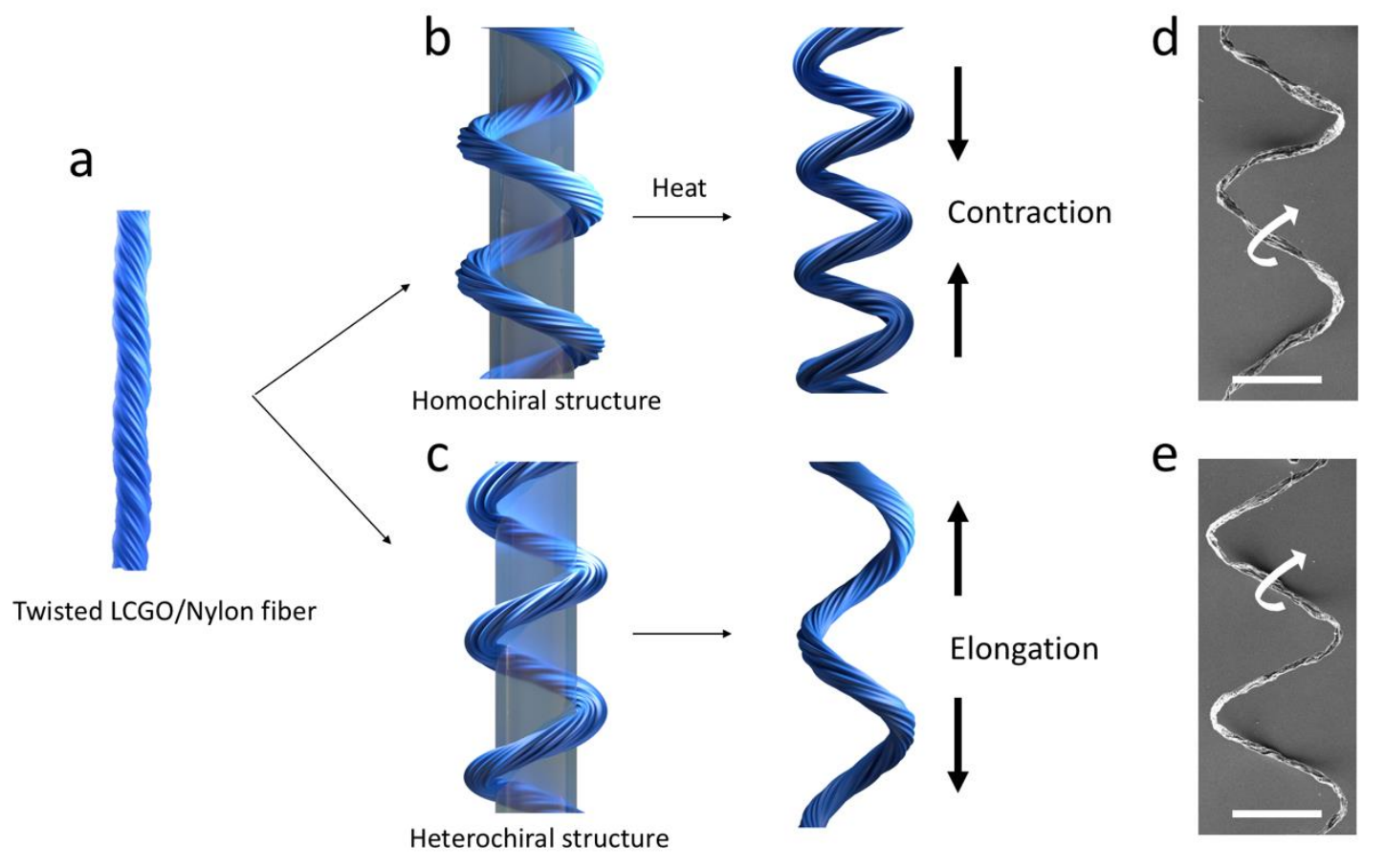

Figure 1. Schematic illustration of the fabrication process used to prepare the LCGO/Nylon tensile actuators. a) S-twisted wet-spun LCGO/Nylon fiber that was wound onto a glass tube with b) S-direction (homochiral structure) or c) Z-direction (heterochiral structure). d) and e) shows scanning electron microscope (SEM) images of the homochiral structure and the heterochiral structure of $\sim 76 \mu \mathrm{m}$ diameter of the LCGO/Nylon tensile actuators, respectively (Scale bar: $1 \mathrm{~mm}$ ). The white arrows indicate fiber twisted direction. 
a

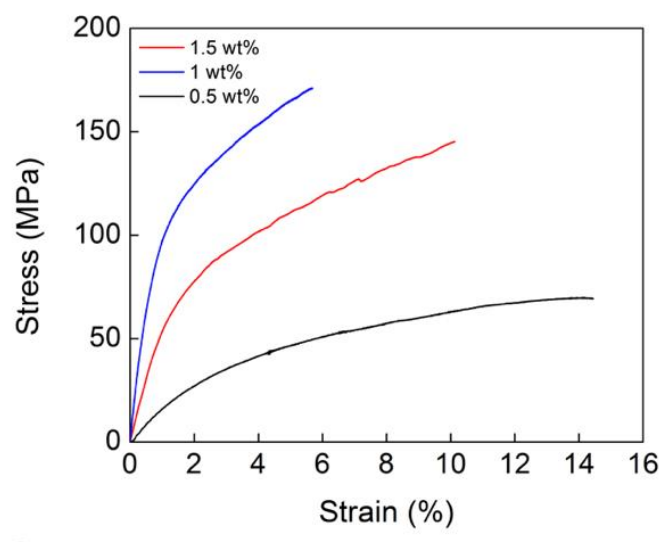

C

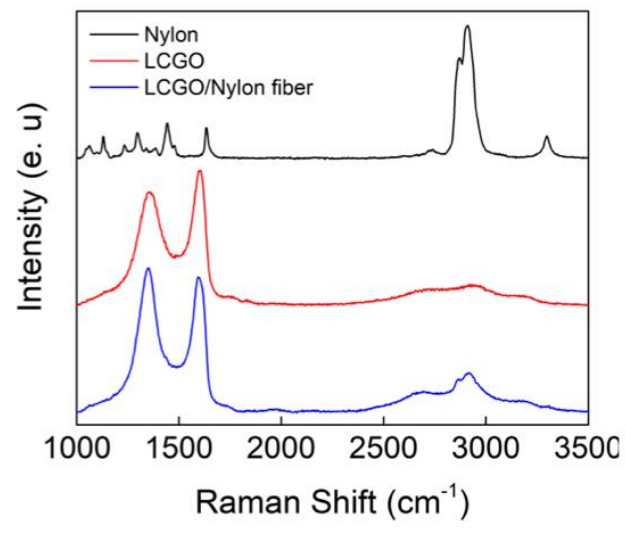

b

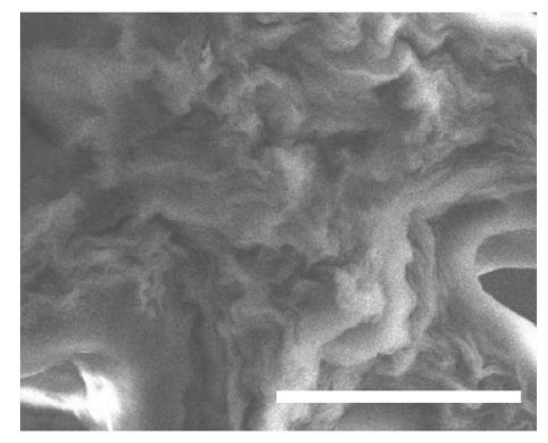

d

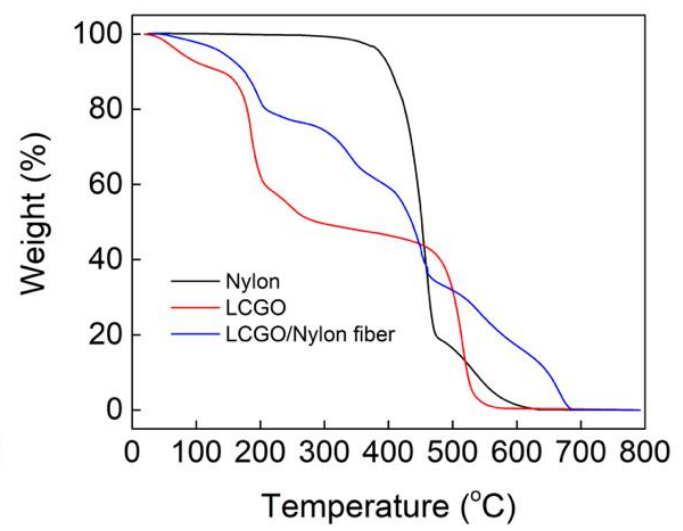

Figure 2. a) Stress-strain curve of the LCGO/Nylon fiber by the LCGO concentration. b) A magnification SEM image of a cross section of the LCGO/Nylon fiber. (Scale bar: 20 um) c) Raman spectra of the Nylon (black), LCGO (red), and LCGO/Nylon fiber (blue). d) Thermogravimetric analysis of the Nylon (black), LCGO (red), and LCGO/Nylon fiber (blue). 

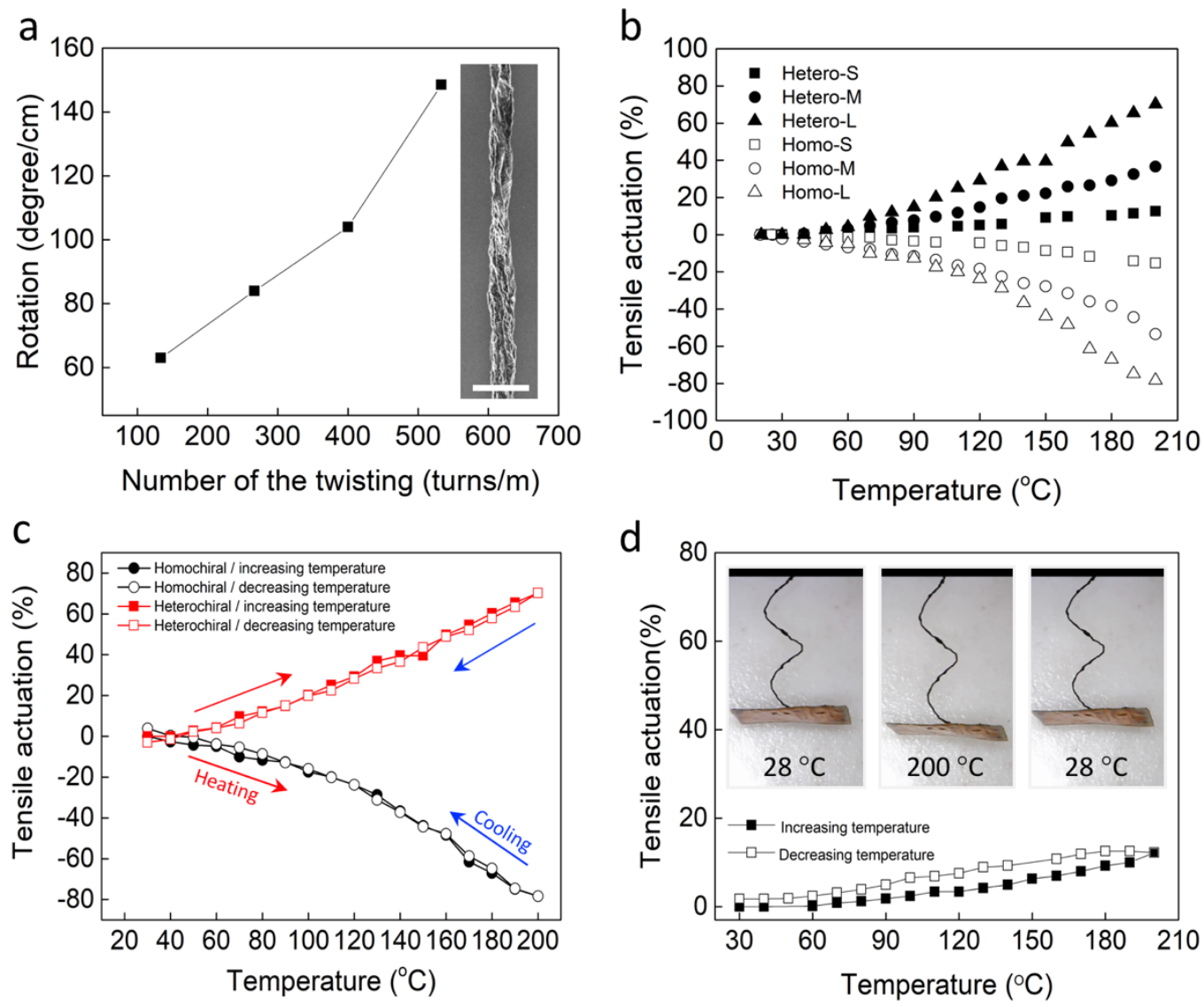

Figure 3. a) Performance of the maximum torsional actuation stroke when heated to $200^{\circ} \mathrm{C}$ and for LCGO/Nylon fibers prepared with different amounts of the twist. The inset shows a SEM image of a 533 turns/m S-twisted LCGO/Nylon fiber with a bias angle of $\sim 26^{\circ}$ (Scale bar: 200 um). Tensile actuation of the heterochiral and homochiral coiled LCGO/Nylon actuators b) by spring index (S: 10.9, M:16.5, L: 24.9). c) Reversible actuation of the homochiral and heterochiral mandrel coiled LCGO/Nylon actuators with low spring indices and when heated and cooled. d) Pictures showing the actuation of the heterochiral structure of LCGO/Nylon actuator $(63.8 \mu \mathrm{g})$ with a tethered $\mathrm{Cu}$ plate $(7.37$ $\mathrm{mg})$. The temperature was increased from room temperature $\left(28^{\circ} \mathrm{C}\right)$ to $200^{\circ} \mathrm{C}$ and cooled again to room temperature. 
a

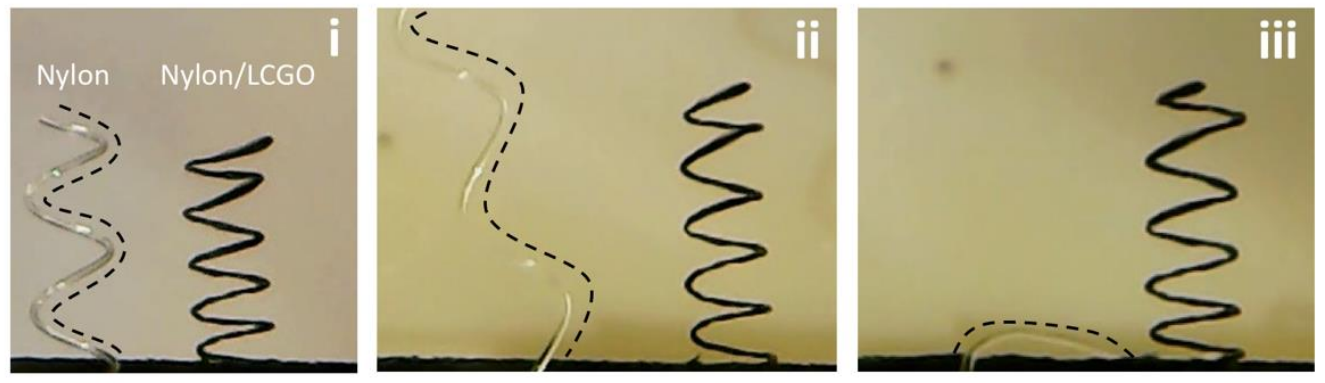

b

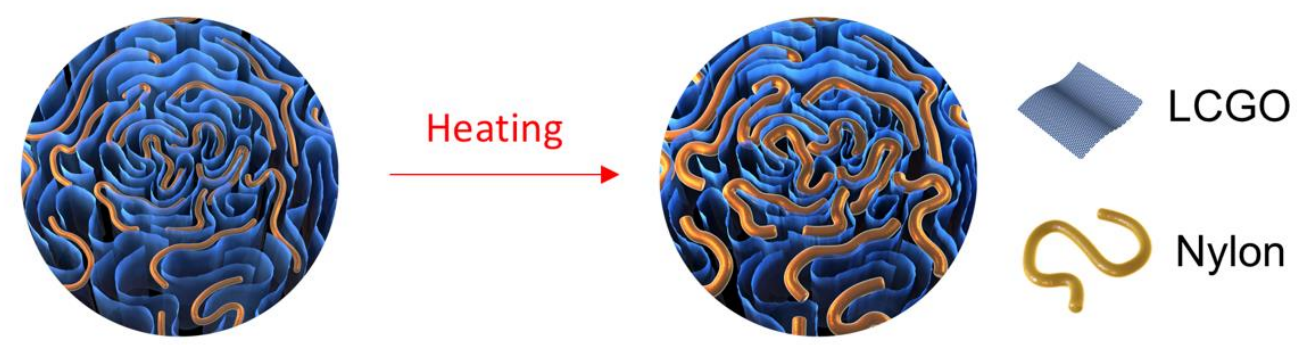

Figure 4. a) Optical images of actuation contrast between twisted and coiled Nylon fiber and LCGO/Nylon heterochiral coil depending on temperature; i) room temperature, ii) $120^{\circ} \mathrm{C}$, and iii) $300^{\circ} \mathrm{C}$ which is above the melting point of the Nylon-6/6 (melting point: $\left.250-260^{\circ} \mathrm{C}\right)$. The dot lines representing the Nylon fiber shape. b) schematic images show the cross-sectional structure before and after heating. 
Graphic for manuscript (Table of Content)

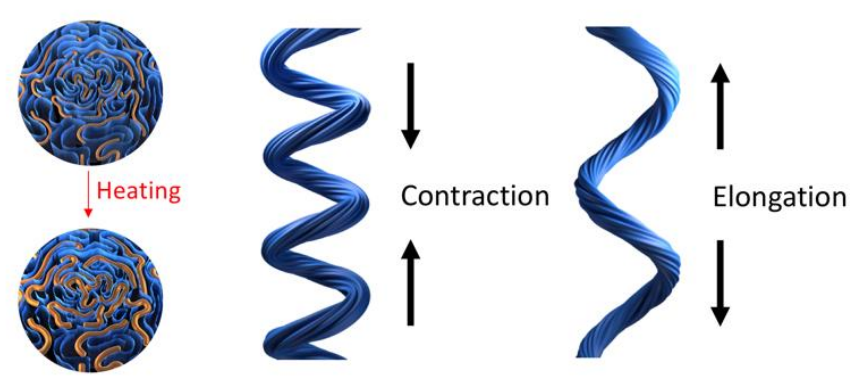

